Received: June, 2017

Accepted: January, 2018

ISSN $2006-6996$

\title{
ISOLATION AND CHARACTERISATION OF ACTIVE PRINCIPLE FROM THE LEAVES EXTRACT OF Fadogia erythrophloea (K. SCHUM. \& K. KRAUSE) HUTCH AND DALZIEL
}

\author{
*Abdullahi Sulaiman ${ }^{1}$, G. I. Ndukwe ${ }^{2}$ and J. O. Amupitan ${ }^{2}$ \\ ${ }^{1}$ Division of Agricultural Colleges, Ahmadu Bello University Zaria, Kaduna-Nigeria. \\ ${ }^{2}$ Department of Chemistry, Ahmadu Bello University Zaria, Kaduna-Nigeria. \\ *Corresponding Author E-Mail: abdulskargi@yahoo.co.uk GSM No.+2348036790734.
}

\begin{abstract}
Fadogia erythrophloea (K. Schum. \& $K$. Krause) Hutch and Dalziel is a specie from the family of Rubiaceae. The plant materials of Fadogia erythrophloea have been used in Africa in alternative medicine to remedy dysentery, malaria, childhood fever, as antidotes (venomous stings, bites, etc.), emetics, vermifuge, colic and constipation. Therefore, this study was designed to isolate active principle(s) present in the leaves extract of Fadogia erythrophloea and to test for possible in-vitro antimicrobial activity. Isolation works were carried out using various chromatographic techniques on the n-butanol fraction; this yielded a pure compound labelled as 'F.e'. From the data obtained through spectroscopic techniques using ${ }^{1} \mathrm{H}$ NMR, ${ }^{13} \mathrm{C}$ NMR, DEPT, COSY, NOESY, HMBC and HSQC Nuclear Magnetic Resonances (NMR), the compound 'F.e' was identified to be an ipolamiide (an iridoid glycoside). Based on the findings in this research work, it can be concluded that the leaves of the plant Fadogia erythrophloea (K.Schum. \& K.Krause) Hutch. \& Dalziel possess measurable in-vitro antimicrobial activity against many of the microorganisms implicated in the pathogenesis of human infections.
\end{abstract}

KEY WORDS: Fadogia erythrophloea, Rubiaceae, Isolation, spectroscopic techniques, iridoid glycoside, ipolamiide, in-vitro antimicrobial activity.

\section{INTRODUCTION}

Medicinal plants are of great importance to the health of individuals and communities. The medicinal value of these plants lies in some chemical substances that produce a definite physiological action on the human body. The most important of these bioactive constituents of plants are alkaloids, tannins, flavonoids, saponins and phenolic compounds (Ndukwe et al., 2011).

The potential for developing antimicrobials from higher plants appears rewarding, as it leads to the development of phytomedicine to act against microbes. Plant based antimicrobials represents a vast untapped source of medicine. Plant based antimicrobials have enormous therapeutic potential, as they can serve the purpose without any side effects that are often associated with synthetic antimicrobials. Therefore, continuous further exploration of plant derived antimicrobials is needed today.

The medicinal effects of phytomedicine typically results from synergistic actions of secondary metabolites present in the plants (Wink, 1999). Plant secondary metabolites have a defensive role against pathogen attack, an attractant role towards pollinators, protective actions to abiotic stresses such as temperature, water status, light levels, UV exposure and mineral nutrients and its role at cellular level as plant growth regulators, modulators of gene expression and in signal transduction have also been shown (Kaufman et al., 1999; Wink, 1999).

In many part of the world, medicinal plant have been used for their antibacterial, antifungal and antiviral activities for hundreds of years (Ali et al., 1998). It is against this background that this work aimed at isolating a bioactive chemical constituent from the leaves extract of Fadogia erythrophloea and test its antimicrobial activity.

\section{MATERIALS AND METHODS}

Collection, Identification and Preparation of Plant Material

The plant materials were collected from the bushes around Faka, Igabi local government area of Kaduna State-Nigeria, in the month of November 2011. It was authenticated with specimen voucher number 940 at the herbarium unit of the Department of Biological Sciences, Ahmadu Bello University Zaria-Nigeria. The plant material were air-dried for 21 days and crushed to coarse powder.

Extraction of the Plant Material

The dried powdered leaves (800 g) was extracted exhaustively with methanol using Soxhlet extractor at a temperature of about $40-50{ }^{\circ} \mathrm{C}$. The extract was concentrated in vacuo $40{ }^{\circ} \mathrm{C}$ using rotary evaporator, and the crude extract (residue) was dried under vacuum.

The methanol extract was partitioned with petroleum ether, chloroform, ethyl acetate and n-butanol.

Thin Layer Chromatography (TLC)

Thin layer chromatography (one way ascending) was carried out on TLC aluminium sheet silica gel $60 \mathrm{PF}_{254}$ pre coated with layer thickness of $0.2 \mathrm{~mm}$.

Column Chromatography

Sample loading: The dry loading method was adopted (Cannell, 1998); The sample was dissolved in minimum amount of suitable organic solvent, mixed with a small quantity of silica gel, dried, triturated and then loaded on top of the previously packed column. 
Solvents System for Elution: Various solvent systems comprising chloroform, chloroform/ethyl acetate, ethyl acetate, ethyl acetate/methanol and finally methanol mixtures were used in eluting the column by gradient.

\section{Antimicrobial Screening}

The Test Organisms

The microorganisms tested were obtained from the Department of Medical Microbiology, Ahmadu Bello University Teaching Hospital (ABUTH) Shika, Zaria. All the isolates were checked for purity and maintained in a slant of nutrient agar.

\section{Standard Antimicrobial Drugs Used}

The investigated microorganisms were tested against standard antimicrobials. Ciprofloxacin $(2 \mu \mathrm{g} / \mathrm{disc})$ was used for the bacterial strains and for fungal strains Fluconazole ( $2 \mu \mathrm{g} / \mathrm{disc}$ ) was used.

\section{Susceptibility Test of the Extract Using Agar Well Diffusion Method}

The disc diffusion method was used (Nostro et al., 2000). The antibacterial activities of the methanol, ethyl acatate and chloroform fractions of the leaves of Fadogia erythrophloea was determined using stock concentration of $100 \mathrm{mg} / \mathrm{ml}$.

\section{Determination of Minimum Inhibitory Concentration (MIC)}

The minimum inhibitory concentrations of the extracts were determined using the tube dilution method as outlined by the National Committee for Clinical Laboratory Standards (NCCLS, 2000).

\section{Determination of Minimum Bactericidal}

\section{Concentrations (MBC)}

The minimum bactericidal concentration of the extract was determined as outlined by the NCCLS (2000), on nutrient agar plates.

Thin Layer Chromatography of the N-Butanol Fraction

The n-butanol fraction of the leaves of Fadogia erythrophloea was subjected to thin layer chromatography using pre-coated TLC aluminium plate. The solvent system used to determine the profile of the extract was chloroform : ethyl acetate : methanol (4:8:4). Four prominent spots were observed after visualization. The plant profile was established using solvent system that gives the best separation, and the best solvent mixture for the column chromatography was determined.

Column Chromatography of the n-butanol Fraction

The n-butanol fraction $(5 \mathrm{~g})$ was mounted over glass column $(75 \mathrm{~cm} \times 3.5 \mathrm{~cm})$ packed with silica gel $(60-$ 120 mesh). The column was eluted continuously using chloroform, chloroform : ethyl acetate, ethyl acetate, ethyl acetate : methanol mixtures and finally methanol as solvent systems by gradient elution technique. The progress of the elution was monitored using thin layer chromatography. A total of 250 fractions of $20 \mathrm{ml}$ aliquot each were collected. The fractions were combined based on their TLC profile to afford five major fractions $F_{1}-F_{5}$, and the column was finally washed with methanol to give the sixth fraction $F_{6}$. Fraction $F_{3}$ which showed one major spot and some minor spots was subjected to gel filtration chromatography on Sephadex $\mathrm{LH}-20$ packed column. The compounds were allowed to descend the column by gravity, when they reached the tap of the column, the column was eluted at a controlled rate with methanol. Twenty five sub-fractions were collected. Fractions 5 - 15 consisting of just a single homogenous spot on TLC were pooled together and coded as 'F.e'. This was concentrated to obtain about $15 \mathrm{mg}$ of a brownish crystal-like solid. 'F.e' was subjected to antimicrobial analysis to establish it susceptibility, and spectroscopic analyses were conducted to elucidate its chemical structure.

\section{RESULTS AND DISCUSSION \\ Antimicrobial Analysis of the Pure Compound 'F.e'}

The antimicrobial analysis result of the pure compound ' $F . e^{\prime}$ revealed its activity against microorganism (Table 1). 'F.e' was found to be sensitive against streptococcus feacalis, Bacillus cereus, Escherichia coli, Shigella dysenteriae, Klebsiella pneumoniae, and Candida albicans. While Staphylococcus aureus, Corynebacterium ulcerans, Proteus mirabilis, Pseudomonas aeruginosa and Candida albicans, were resistant to the pure compound.

Table 1: Antimicrobial screening of the isolated pure compound

\begin{tabular}{lccc}
\hline Test organism & 'F.e' & Ciprofloxacin & Fluconazole \\
\hline Staphylococcus aureus & $\mathrm{S}$ & $\mathrm{S}$ & $\mathrm{R}$ \\
Staphylococcus pyogenes & $\mathrm{R}$ & $\mathrm{S}$ & $\mathrm{R}$ \\
Bacillus cereus & $\mathrm{S}$ & $\mathrm{S}$ & $\mathrm{R}$ \\
Corynebacterium ulcerans & $\mathrm{S}$ & $\mathrm{S}$ & $\mathrm{R}$ \\
Escherichia coli & $\mathrm{S}$ & $\mathrm{S}$ & $\mathrm{R}$ \\
Pseudomonas aeruginosa & $\mathrm{S}$ & $\mathrm{S}$ & $\mathrm{R}$ \\
Shigella dysenteriae & $\mathrm{S}$ & $\mathrm{S}$ & $\mathrm{R}$ \\
Klebsiella pneumonia & $\mathrm{S}$ & $\mathrm{R}$ & $\mathrm{R}$ \\
Candida albicans & $\mathrm{R}$ & $\mathrm{R}$ & $\mathrm{S}$ \\
Candida Krusei & $\mathrm{S}$ & $\mathrm{R}$ & $\mathrm{S}$ \\
\hline
\end{tabular}

Key: $\mathrm{S}=$ Sensitive, $\mathrm{R}=$ Resistant

Zone of Inhibition of the Pure Compound 'F.e' The mean zones of inhibition produced against the test microorganisms ranged between $24-32 \mathrm{~mm}$. The highest zone of inhibition was obtained for Bacillus cereus to be $32 \mathrm{~mm}$. Among all the microbial strains investigated, Staphylococcus aureus, Corynebacterium ulcerans, Proteus mirabilis, Pseudomonas aeruginosa and Candida krusei were the most resistant strains, which did not show any activity at all. 
Streptococcus feacalis,Bacillus cereus, Escherichia coli, Shigella dysenteriae, Klebsiella pneumoniae, and Candida albicans were the most susceptible bacterias (Table 2). The extract was compared to the standard antibiotics. The standard antimicrobics used for bacterial strains were Ciprofloxacin $(2 \mu \mathrm{g} / \mathrm{ml})$ and that for fungal strains was Fluconazole $(2 \mu \mathrm{g} / \mathrm{ml})$.

Table 2: Zone of Inhibition ( $\mathrm{mm}$ ) of the Pure Compound 'F.e' against Test Organisms

\begin{tabular}{lcccc}
\hline Test organism & 'F.e' $(\mathrm{mm})$ & DMSO & Ciprofloxacin & Fluconazole \\
\hline Staphylococcus aureus & 0 & 0 & 37 & 0 \\
Streptococcus feacalis & 24 & 0 & 42 & 0 \\
Bacillus cereus & 32 & 0 & 40 & 0 \\
Corynebacterium ulcerans & 0 & 0 & 32 & 0 \\
Escherichia coli & 27 & 0 & 27 & 0 \\
Shigella dysenteriae & 30 & 0 & 32 & 0 \\
Klebsiella pneumonia & 28 & 0 & 37 & 0 \\
Proteus mirabilis & 0 & 0 & 27 & 0 \\
Pseudomonas aeruginosa & 0 & 0 & 0 & 0 \\
Candida albicans & 25 & 0 & 0 & 27 \\
Candida krusei & 0 & 0 & 0 & 32 \\
\hline
\end{tabular}

Key: 0 = Resistant

\section{MIC of the Pure Compound 'F.e'}

The Minimum Inhibitory Concentrations of the pure compound 'F.e' of Fadogia erythrophloea are reported in Table 3. The results showed MIC ranging from 2.5 $\mu \mathrm{g} / \mathrm{ml}$ to $40 \mu \mathrm{g} / \mathrm{ml}$. The pure compound 'F.e' inhibited the growth of Streptococcus feacalis and Candida albicans at a concentration of $10 \mu \mathrm{g} / \mathrm{ml}$. Bacillus cereus, Escherichia coli, Shigella dysenteriae, and Klebsiella pneumoniae, at a constant concentration of $5 \mu \mathrm{g} / \mathrm{ml}$. The pure ' $F . \mathrm{e}^{\prime}$ was totally inactive at all concentrations against Staphylococcus aureus, Corynebacterium ulcerans, Proteus mirabilis, Pseudomonas aeruginosa, and candida krusei.

Table 3: MIC of the Pure Compound 'F.e'

\begin{tabular}{|c|c|c|c|c|c|}
\hline Test organism & $40 \mu \mathrm{g} / \mathrm{ml}$ & $20 \mu \mathrm{g} / \mathrm{ml}$ & $10 \mu \mathrm{g} / \mathrm{ml}$ & $5 \mu \mathrm{g} / \mathrm{ml}$ & $2.5 \mu \mathrm{g} / \mathrm{ml}$ \\
\hline \multicolumn{6}{|l|}{ Staphylococcus aureus } \\
\hline Streptococcus feacalis & - & - & MIC & + & ++ \\
\hline Bacillus cereus & - & - & - & MIC & + \\
\hline \multicolumn{6}{|c|}{ Corynebacterium ulcerans } \\
\hline Escherichia coli & - & - & - & MIC & + \\
\hline Shigella dysenteriae & - & - & - & MIC & + \\
\hline \multicolumn{6}{|l|}{ Proteus mirabilis } \\
\hline \multicolumn{6}{|c|}{ Pseudomonas aeruginosa } \\
\hline $\begin{array}{l}\text { Candida albicans } \\
\text { Candida krusei }\end{array}$ & - & - & MIC & + & ++ \\
\hline
\end{tabular}

Key: $-=$ No turbidity (no growth), MIC= Minimum inhibitory concentration, $+=$ Turbid (light growth), $++=$ Moderate turbidity, $+++=$ High turbidity

\section{MBC/MFC of the Pure Compound 'F.e'}

The minimum bactericidal/fungicidal concentrations of the crude methanol extracts of Fadogia erythrophloea are reported in Table 4. The results showed MBC/MFC ranging from $2.5 \mu \mathrm{g} / \mathrm{ml}$ to $40 \mu \mathrm{g} / \mathrm{ml}$. The MBC/MFC of the pure 'F.e' for Bacillus cereus was $10 \mu \mathrm{g} / \mathrm{ml}$, and for Streptococcus feacalis, Escherichia coli, Shigella dysenteriae, Klebsiella pneumoniae, and Candida albicans were observed as $20 \mu \mathrm{g} / \mathrm{ml}$. The pure compound was totally inactive at all concentrations against Staphylococcus aureus, Corynebacterium ulcerans, Proteus mirabilis, Pseudomonas aeruginosa and Candida krusei. 
Table 4: MBC/MFC of the Pure Compound 'F.e'

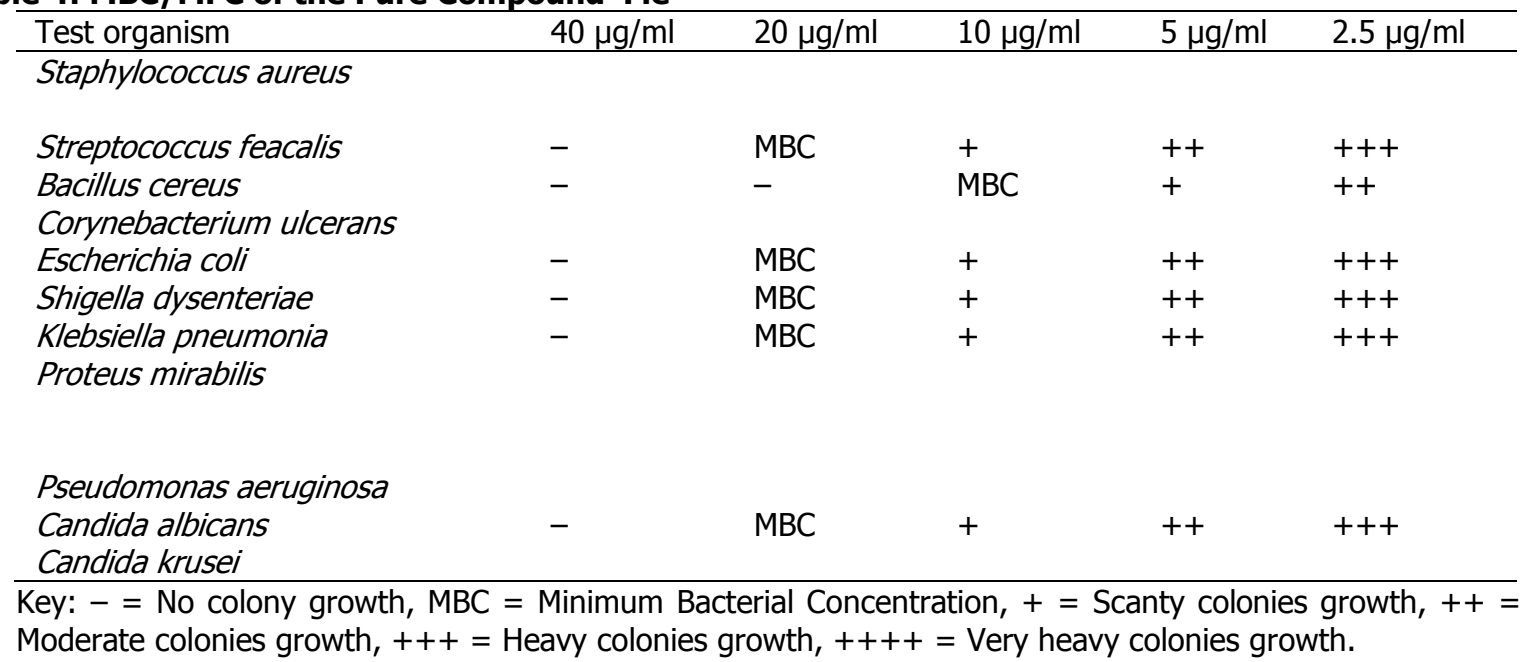

\section{Characterization and Structural Elucidation of the Pure Compound 'F.e'}

Compound 'F.e' was obtained as a pure brownish amorphous compound, with melting point range 139 ${ }^{0} \mathrm{C}-142{ }^{\circ} \mathrm{C}$. The pure compound 'F.e' was subjected to Nuclear Magnetic Resonance NMR Spectroscopy at School of Chemistry, University of KwaZulu-Natal, Westville Campus, Private Bag X54001, Durban 4000, South Africa. The sample was analysed and the following spectrum were obtained; Proton NMR spectra, ${ }^{13} \mathrm{C}$ NMR spectra, Distortionless Enhancement by Polarization Transfer DEPT NMR spectra, Correlated SpectroscopY COSY spectra, Nuclear Overhauser Experiment SpectroscopY NOESY spectra, Heteronuclear Multiple-Bond Correlation HMBC spectra, and Heteronuclear Single-Quantum Correlation HSQC spectra.

\section{${ }^{13} \mathrm{C}$ NMR Spectrum of Compound 'F.e'}

The ${ }^{13} \mathrm{C}$ NMR spectrum of 'F.e' (Appendix I) showed 17 carbon signals, six of which could be assigned to a $\beta$-glucopyranosyl moiety, and the highest chemical shift at $168.0972 \mathrm{ppm}$ is characteristic of an ester.

The following are the ${ }^{13} \mathrm{C}$ chemical shifts, with the corresponding position of the carbon atoms;

13C NMR (125 MHz, CD $\left.{ }_{3} \mathrm{OD}\right): \delta_{C} 168.09$ (C-11), 152.63 (C-3), 115.23 (C-4), $99.62\left(\mathrm{C}-1^{\prime}\right), 94.25(\mathrm{C}-1)$,

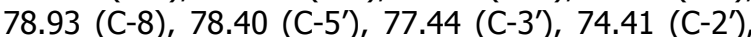
71.72 (C-5), $71.70\left(\mathrm{C}-4^{\prime}\right), 62.84\left(\mathrm{C}-6^{\prime}\right), 61.68$ (C-9), 51.69 (COOCH3), 40.40 (C-7), 38.87 (C-6), 23.28 (C10).

\section{Dept NMR Spectrum of Compound 'F.e'}

The DEPT NMR spectrum of 'F.e' (Appendix II) showed the presence of one methyl carbon atom signal, three methylene carbon atoms signals, ten methine carbon atoms signals and four quaternary carbon atoms signals.

\section{${ }^{1} \mathrm{H}$ NMR Spectrum of Compound 'F.e'}

The ${ }^{1} \mathrm{H}$ NMR spectrum (Appendix III) of 'F.e' exhibited the characteristic signals for an iridoid structure and showed the presence of a methoxy carbonyl function at $\delta_{H} 3.73$, and a tertiary methyl group at $\delta_{H}$ 1.15.In addition, resonances arising from two methylene groups were observed. The ${ }^{1} \mathrm{H}$ NMR signal at $\delta_{H} 4.58$ was assigned to the anomeric proton of a $\beta$ glucopyranose unit.

1H NMR (500 MHz, CD $\mathrm{OD}): \delta_{H} 7.4(3 \mathrm{H}, \mathrm{H}-3), 5.8$ $(1 \mathrm{H}, \mathrm{H}-1), 4.5\left(1 \mathrm{H}, \mathrm{H}-1^{\prime}\right), 3.9\left(1 \mathrm{H}, \mathrm{H}-6^{\prime} b\right), 3.8(3 \mathrm{H}$, $\left.\mathrm{COOCH}_{3}\right), 3.7\left(1 \mathrm{H}, \mathrm{H}-6^{\prime} a\right), 3.5\left(1 \mathrm{H}, \mathrm{H}-5^{\prime}\right), 3.4(1 \mathrm{H}, \mathrm{H}-$ $\left.3^{\prime}\right), 3.3\left(1 \mathrm{H}, \mathrm{H}-4^{\prime}\right), 3.2\left(1 \mathrm{H}, \mathrm{H}-2^{\prime}\right), 2.4(1 \mathrm{H}, \mathrm{H}-9), 2.3$ $(1 \mathrm{H}, \mathrm{H}-6 b), 2.0(1 \mathrm{H}, \mathrm{H}-7 b), 1.9(1 \mathrm{H}, \mathrm{H}-6 a), 1.6(1 \mathrm{H}$, $\mathrm{H}-7 \mathrm{a}), 1.1\left(3 \mathrm{H}, \mathrm{H}_{3}-10\right)$.

\section{Structural Elucidation}

The signal $\delta_{H} 5.8$ which was shifted down field is due to glycosidation, this indicated the attachment of the $\beta$-glucopyranose unit at the carbon atom $\delta_{C} 94.1$ of the iridoid aglycone. The splitting patterns of the protons with chemical shift values $\delta_{\mathrm{H}} 7.4$ and $\delta_{\mathrm{H}} 2.4$ were suggestive of the carbon atoms with chemical shifts $\delta_{C} 115.1, \delta_{C} 71.6$ and $\delta_{C} 78.9$ to be substituted. Thus, the methoxycarbonyl group was assigned to be positioned at $\delta_{C} 115.1$ carbon atom, due to the highly deshielded signal of the proton $\delta_{\mathrm{H}} 7.4$, and the quaternary carbon resonance at $\delta_{C}$ 71.6. The complete analysis of the ${ }^{1} \mathrm{H}$ and ${ }^{13} \mathrm{C}$ NMR data of compound 'F.e' allowed the assignments of the multiplet signals observed at $\delta_{H} 2.3 / 1.9$ and $\delta_{H}$ 2.0/1.6 to the methylene protons at the carbon atoms $\delta_{C} 38.8$ and $\delta_{C} 40.3$ respectively. The multiplicity of the proton $\delta_{\mathrm{H}} 2.4$ was also indicative of a totally substituted carbon atom at $\delta_{C}$ 78.9. However, the chemical shift value of the tertiary methyl group $\delta_{H}$ 1.1 suggested its attachment to the carbon atom at $\delta_{C}$ 78.9. On the other hand, the chemical shift values of both $\delta_{C} 78.9$ and $\delta_{H} 1.1$ also indicated the presence of a tertiary hydroxyl function at the carbon atom with $\delta_{C} 78.9$ chemical shift.

All structural assignments were confirmed by the results obtained from the $2 \mathrm{D}$ shift-correlated ${ }^{1} \mathrm{H}-{ }^{1} \mathrm{H}$ COSY, ${ }^{1} \mathrm{H}-{ }^{13} \mathrm{C}$ HSQC and HMBC experiments of ' $F . \mathrm{e}^{\prime}$ (Ersöz et al., 2002).

Proposed Structure of Compound 'F.e'

The proposed structure of compound ' $F . e^{\prime}$ which was confirmed to be Ipolamiide from Table 5, is as shown below, with the relative carbon positions and some important chemical shifts. 
<smiles>COC(=O)C1=COC(O[C@H]2O[C@H](CO)[C@@H](O)[C@H](O)[C@H]2O)C2C1CCC2(C)O</smiles>

Structure of compound 'F.e' = Ipolamiide

\section{SOLUBILITY TEST OF COMPOUND 'F.e'}

The compound 'F.e' was observed to be water soluble, and it was easily hydrolysed by Hydrochloric acid (5\%).

\section{CONCLUSION}

The results showed that the isolate from the leaves extracts of Fadogia erythrophloea possessed measurable in-vitro antimicrobial activity against many of the microorganisms implicated in the pathogenesis of human infections. The broad range of

\section{APPENDIX I}

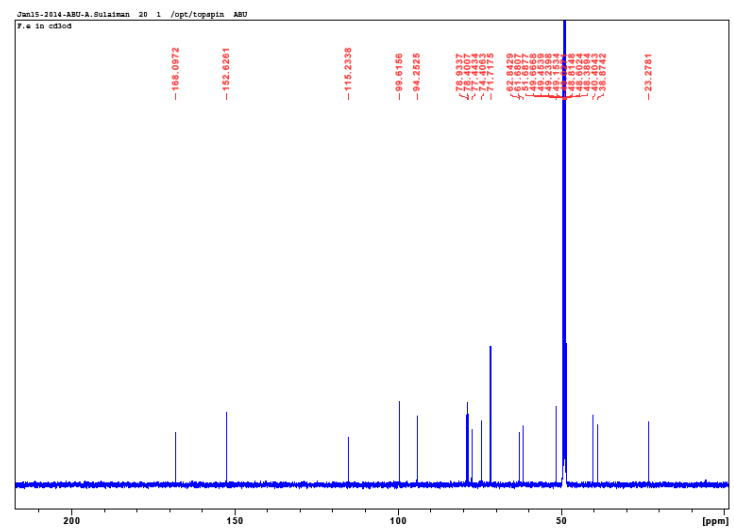

${ }^{13} \mathrm{C}$ NMR Spectrum of pure compound 'F.e.'

\section{APPENDIX III}

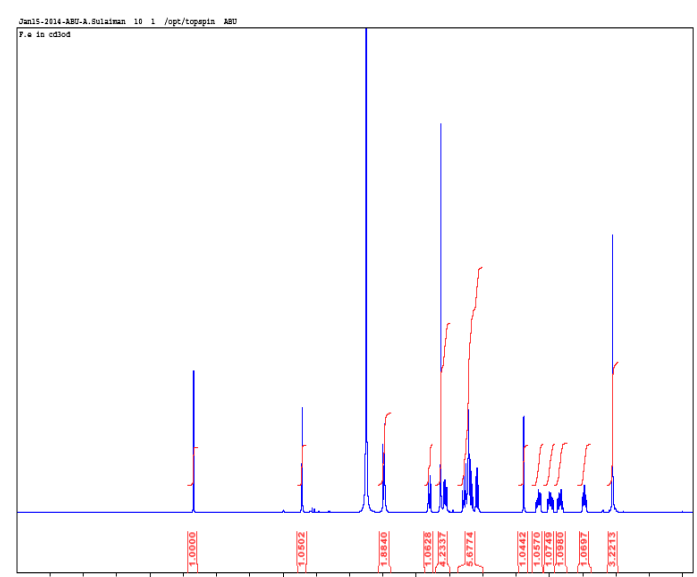

inhibition found implied that the isolate had a comparable antimicrobial activity. Hence the significant antimicrobial activity of the leaves extracts could be ascribed to the presence of this active principle. Based on the findings in this work, it can be concluded that ipolamiide was isolated from Fadogia erythrophloea, with significant antimicrobial activity on Streptococcus feacalis, Bacillus cereus, Escherichia coli, Shigella dysenteriae, Klebseilla pneumonia and Candida albicans.

\section{APPENDIX II}

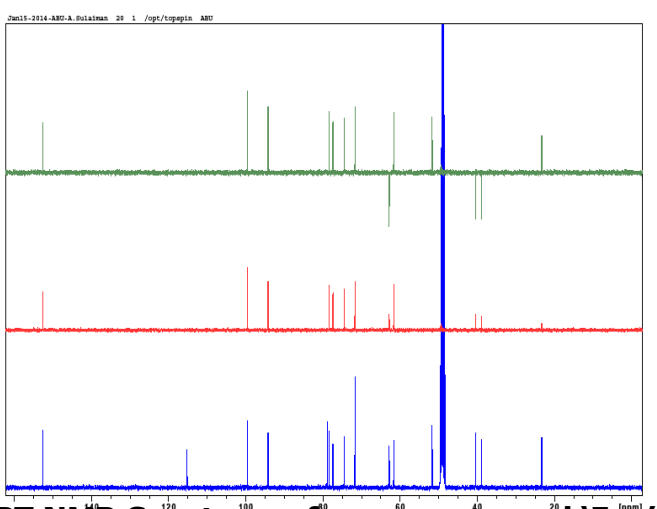

DEPT NMR Spectrứm of pure compound 'F.e.' 


\section{REFERENCES}

Ali, M. S., Yaghmour, R. M. and Faidi, Y. R. (1998). Antimicrobial Activity of 20 Plants used in Folkloric Medicine in the Palestinian Area. Journal of Ethnopharmacology, 60: 256-271.

Cannell, R. J. P. (1998). Natural Products Isolation: Volume 4 of Methods in Biotechnology. Humana Press. pp. 473.

Ersöz, T., Yalçin, F. N., Akbay, P., Çaliş, İ., Dönmez, A. A. and Sticher, O. (2003). Iridoid and Phenylpropanoid Glycosides from Phlomis samia, Phlomis monocephala and Phlomis carica. Turkey Journal of Chemistry. 27: 295305

Kaufman, P. B., Cseke, L. J., Warber, S., Duke, J. A. and Brielmann, H. L. (1999). Natural Products from Plants.CRC Press, Boca Raton, FL.
National Committee for Clinical Laboratory Standards (2000).Methods for Dilution Antimicrobial Susceptibility Tests for Bacteria that Grow Aerobically. Approved Standard, $5^{\text {th }}$ ed. NCCLS Documents M7-A5. Villanova.

Ndukwe, G. I., Bello, I. A., Audu, O. T. and Habila, J. D. (2011). A Bioactive Flavonoid from Pavette crisspes.Organic and Medicinal Chemistry Letters, 1:14. Retrieved from http://www.orgmedchemlett.com/content/1/ $1 / 14$.

Nostro, A., Germano, M. P., D'Angelo, Marino, A. and Cannatelli, M. A. (2000). Extraction Methods and Bio-autography for Evaluation of Medicinal Plant Antimicrobial Activity. Letter of Applied Microbiology, 30: 379-384.

Wink, M. (1999). Introduction Biochemistry, Role and Biotechnology of Secondary Products. In: Wink, M. (ed.), Biochemistry of Secondary Product Metabolism. CRC Press, Boca Raton, FL. pp. 1-16. 